\title{
Maternal lactation characteristics after consumption of an alcoholic soup during the postpartum 'doing-the-month' ritual
}

\author{
Yeh-Chung Chien ${ }^{1}$, Ya-Jing Huang ${ }^{2}$, Chun-Sen $\mathrm{Hsu}^{3}$, Jane C-J Chao ${ }^{2}$ and \\ Jen-Fang Liu ${ }^{2, *}$ \\ 'Department of Industrial Safety and Health, Hungkuang University, Taichung, Taiwan, Republic of China: \\ ${ }^{2}$ School of Nutrition and Health Science, Taipei Medical University, 250 Wu-Hsing Street, Taipei 110, Taiwan, \\ Republic of China: ${ }^{3}$ Department of Gynecology and Obstetrics, Taipei Medical University, Wan-Fang Hospital, \\ Taipei, Taiwan, Republic of China
}

Submitted 24 March 2007: Accepted 24 February 2008: First published online 22 April 2008

\begin{abstract}
Objective: The present study examined whether ethanol exposure influences lactation parameters. Specifically, selected constituents in maternal blood and milk and the lactation performance of Chinese lactating mothers were evaluated after they had consumed chicken soup flavoured with sesame oil and rice wine (CSSR), a diet traditionally prescribed during the postpartum 'doing-the-month' ritual.

Design: Twenty-three lactating mothers were examined. Informed consent was obtained from each subject. Each subject was tested on two occasions separated by a week. The target alcohol dosage was $0 \cdot 3 \mathrm{~g} / \mathrm{kg}$ body weight. Milk and blood samples were collected prior to consumption of soup and at 120 and $150 \mathrm{~min}$, respectively, after consumption. Levels of various constituents were measured. The time for ejection of the first milk droplet and total milk volume yielded were also measured.

Results: Consumption of CSSR influenced TAG, insulin and lactate levels in maternal blood. Likewise, consumption of the soup affected milk composition and its nutritional status, particularly total protein, TAG, fatty acid, $\beta$-hydroxybutyrate and lactate levels. CSSR intake significantly affected TAG and lactate levels in milk. The time for the first milk droplet to be ejected was significantly longer in the CSSR group, indicating that the milk-ejecting reflex is inhibited. However, blood prolactin level increased slightly after ethanol intake. Milk yields were reduced after ingestion of CSSR although the difference was not statistically significant.

Conclusion: Consumption of CSSR affects not only the composition of maternal blood and milk, but also lactation performance. These findings suggest that an alcoholic diet should be avoided during lactation.
\end{abstract}

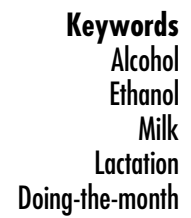

Although breast milk is a valuable food source with confirmed merits, it may not be appropriate in all circumstances ${ }^{(1-7)}$. Chemicals, particularly ethanol, imbibed in accordance with maternal traditions have drawn attention because they can be passed to nursing infants through breast milk $^{(8,9)}$. In certain ethnic traditions, lactating mothers are encouraged to consume alcoholic beverages as a galactagogue $^{(10,11)}$ or to sedate their infants ${ }^{(12)}$. In such cases, ethanol ingested by breast-feeding mothers is passed to nursing infants through breast milk. Chicken soup flavoured with sesame oil and rice wine (CSSR), which is consumed by Taiwanese (ethnically Chinese) mothers during the traditional Chinese 'doing-the-month' ritual, is another example of the mother-milk-infant exposure pathway ${ }^{(13)}$. 'Doing the month' is a $30 \mathrm{~d}$, culturally defined postpartum period of prescribed behaviours such as eating certain foods deemed beneficial to convalescing mothers. The ingredients in CSSR are believed to benefit new mothers by enhancing energy and protein intake, increasing peripheral blood circulation, and thus facilitating recovery by redressing the 'hot-cold' imbalance resulting from pregnancy ${ }^{(14)}$.

Apart from the potential health effects imposed directly on breast-fed infants ${ }^{(15,16)}$, ethanol intake during lactation has been found to alter the metabolism of lipid and other ingredients in the milk of mammals ${ }^{(17-20)}$, hence changing the composition of breast milk and its nutritional status. Additionally, maternal ethanol intake also inhibits the release of suckling-induced oxytocin and attenuates the milk-ejecting reflex ${ }^{(21-23)}$, likely resulting in less milk production $^{(24)}$ and less milk consumption by the breast-fed 
infant ${ }^{(9)}$. Although CSSR is typically prescribed during the Taiwanese Tso-Yueh-Tzu (also known as 'doingthe-month') ritual, its effects on lactation characteristics have not been investigated.

The present study examined whether the traditional Chinese alcoholic diet (CSSR) affects lactation parameters and causes short-term changes in maternal milk and blood composition.

\section{Methods}

\section{Study protocol}

The study design followed those of previous studies ${ }^{(9,24)}$. In particular, a within-subject repeated measurement was applied to control for individual variation. Each subject was tested on two days with a 1-week interval and randomly received either CSSR (exposure section) or NASC (nonalcoholic sesame oil-flavoured chicken soup, control section). Each subject was tested approximately $15 \mathrm{~d}$ after delivery. The experiment was conducted at a commercial Tso-Yueh-Tzu centre, a maternity health-care setting where subjects reside for about a month after discharge from hospital. Blood and milk samples were obtained from each subject at fixed time points during a $3 \mathrm{~h}$ test period after imbibing CSSR or NASC. Various constituents in the samples were determined. The study protocol was reviewed and approved by The Committee on Human Study at Taipei Medical University (Taipei, Taiwan).

\section{Subject selection}

The enrolment criterion for the study was that CSSR was part of subjects' normal diet after delivery. Twenty-three healthy, non-smoking expectant mothers were recruited from the gynaecology and obstetrics clinics at Taipei Medical University Wan-Fang Hospital (Taipei, Taiwan). Informed consent was obtained from each subject prior to the study. Testing commenced approximately $15 \mathrm{~d}$ after delivery. Average age, height, weight, BMI and body adipose rate of the subjects was 24.5 (sD 3.4 ) years, $158 \cdot 8$ (SD 6.5$) \mathrm{cm}, 62.5$ (sD 9.6) kg, $24 \cdot 6$ (SD $2 \cdot 6$ ) $\mathrm{kg} / \mathrm{m}^{2}$ and $37 \cdot 1$ (SD 6.6) \%, respectively. Nineteen mothers were primiparous and four were multiparous.

\section{Preparation of stimuli}

In the present study, CSSR comprised black sesame oil, de-boned chicken breast, aged ginger and rice wine (alcohol 19.5\%; Taiwan Tobacco and Liquor Co., Taiwan) and was prepared in accordance with commercially available recipes. Based on such preparation method, the alcohol level in CSSR reached approximately $40 \mathrm{mg} / \mathrm{ml}$ by continuous boiling for $65 \mathrm{~min}$. Alcohol concentrations in CSSR were stable (variable within $\pm 4 \%$ of the initial level) under freezing $\left(-10^{\circ} \mathrm{C}\right)$ for 1 month. The CSSR thus prepared was stored in a freezer in small individual portions (soup liquid only) for experimental use. Since the entire study was conducted over a period of several months, CSSR was prepared on three different occasions, and alcohol levels and other macronutrients were analysed after each preparation. Analysis of CSSR by GC equipped with a flame ionization detector revealed alcohol levels of 40.65 (sD 1.82$) \mathrm{mg} / \mathrm{ml}^{(13)}$. A target alcohol dosage of $0.30 \mathrm{~g} / \mathrm{kg}$ body weight was achieved by administering to each subject $\sim 8 \mathrm{ml}$ of soup per kilogram of body weight. As the amounts and frequencies of CSSR consumed during the 'doing-the-month' period are subjective, this alcohol level was comparable with that used in other studies and reportedly produced a widely favoured taste. The nonalcoholic chicken soup flavoured with sesame oil (NASC) used as control was prepared using a similar method to that employed in CSSR preparation.

\section{Experimental procedure}

Subjects were asked to refrain from alcohol consumption for three days prior to the experiment to ensure a low baseline alcohol level; compliance was confirmed by $3 \mathrm{~d}$ dietary records ${ }^{(9)}$.

On the morning of the sampling day, subjects (after fasting for $8 \mathrm{~h}$ ) were weighed, blood samples $(10 \mathrm{ml})$ were taken by in-dwelling catheter and milk from each breast was emptied by electric breast pump. Milk and blood samples collected at this stage were used as baseline levels (time 0$)$. Two servings of a cereal snack ( $\sim 630 \mathrm{~kJ}$ $(\sim 150 \mathrm{kcal}))$ were then administered to each subject before CSSR or NASC intake. After $1 \mathrm{~h}$, CSSR or NASC, which was heated in a microwave oven, was consumed by the subjects within $15 \mathrm{~min}$. Subjects were allowed to tend to their infants but were instructed not to breast-feed.

After consumption of CSSR, milk samples $(2 \mathrm{ml})$ were obtained by means of an electric breast pump from each subject at 10, 20, 30, 40, 60 and $90 \mathrm{~min}$, for alcohol analysis. At $120 \mathrm{~min}$ after consuming CSSR or NASC, milk was emptied from both breasts ( $15 \mathrm{~min}$ for each breast) by electric breast pump and pooled. Since this procedure required $30 \mathrm{~min}$ ( $15 \mathrm{~min}$ for each breast), the mid-point (135 $\mathrm{min}$ ) was adopted as the sampling time for further analysis. The volume excreted and the time required for ejection of the first milk droplet were recorded. Venous blood samples $(2 \mathrm{ml})$ were obtained using an in-dwelling catheter at 20, 40, 60 and $90 \mathrm{~min}$ after intake of CSSR for alcohol analysis. At $150 \mathrm{~min}$ after consumption of both soups, venous blood samples $(10 \mathrm{ml})$ were obtained from each subject and analysed for the test constituents. The blood samples were drawn into Vacutainer tubes containing heparin salt ${ }^{(25)}$. Blood and milk samples were centrifuged at 2000 and $4000 \mathrm{rpm}$, respectively, and the supernatants were then stored at $-80^{\circ} \mathrm{C}$ until further analysis.

\section{Sample analysis}

Analysis of macronutrients in soups

The standard methods of the Association of Official Analytical Chemists ${ }^{(26)}$ were used to analyse the macronutrient 
levels in CSSR and NASC, i.e. water, crude ash, crude protein, crude fat, carbohydrates and energy. Specifically, water and crude ash were determined by a heat evaporation/weighing method; crude protein was analysed using Kjeldahl- $\mathrm{H}_{2} \mathrm{SO}_{4}$ titration; crude fat was determined by hexane extraction and a heat evaporation/weighing method; carbohydrates were estimated by subtracting the weights of water, crude ash, crude protein and crude fat from the sample; and energy level was calculated using the formula: energy $(\mathrm{kcal})=[$ crude protein $(\mathrm{g})] \times 4+$ [carbohydrates $(\mathrm{g})] \times 4+[$ crude fat $(\mathrm{g})] \times 9$. The concentrations of these constituents were $83 \cdot 72(\mathrm{SD} 0 \cdot 00) \mathrm{g} / \mathrm{dl}$, $0 \cdot 41(\mathrm{sD} 0 \cdot 01) \mathrm{g} / \mathrm{dl}, 1 \cdot 39(\mathrm{sD} \mathrm{0} 01) \mathrm{g} / \mathrm{dl}, 1.95(\mathrm{sD} 0 \cdot 12) \mathrm{g} / \mathrm{dl}$, $1 \cdot 51(\mathrm{SD} 0 \cdot 03) \mathrm{g} / \mathrm{dl}$ and $120 \cdot 5(\mathrm{sD} 4 \cdot 6) \mathrm{kJ} / \mathrm{dl}(28 \cdot 8(\mathrm{SD} 1 \cdot 10)$ $\mathrm{kcal} / \mathrm{dl})$, respectively.

\section{Analysis of blood and milk composition}

Composition of blood (serum) was analysed by commercial RIA-based test kits. Specifically, TAG (mg/dl), total protein $(\mathrm{mg} / \mathrm{dl})$, glucose $(\mathrm{mg} / \mathrm{dl})$, cholesterol $(\mathrm{mg} /$ dl), glutamic oxaloacetic transaminase (GOT, U/l) and glutamic pyruvic transaminase (GPT, U/1) were analysed using Kodak Ektachem Clinical Chemistry slides (TRIG Slide, TP Slide, GLU Slide, CHOL Slide, GOT Slide and GPT Slide, respectively) from Eastman Kodak Company (NY, USA); insulin $(\mu \mathrm{U} / \mathrm{l})$ was determined using an immunology analyser (Roche Elecsys System 1010) from F. Hoffmann-La Roche Ltd (Basel, Switzerland); and prolactin $(\mathrm{ng} / \mathrm{ml})$ was analysed with a Prolactin MAIAclone kit from Adaltis Italia SpA (Bologna, Italy). Similarly, the commercial assay kits NEFA FA115, Ranbut RB 1007 and Lactate LC 2389 from Randox Laboratories Ltd (Crumlin, UK) were used for determination of NEFA $(\mathrm{mmol} / \mathrm{l}), \beta$-hydroxybutyrate $(\mathrm{mmol} / \mathrm{l})$ and lactate $(\mathrm{mg} / \mathrm{dl})$, respectively. The analysis was performed by a certified laboratory.

Milk constituents were analysed by commercial test kits and in accordance with methods described elsewhere. Total protein $(\mathrm{mg} / \mathrm{dl}), \beta$-hydroxybutyrate $(\mathrm{mmol} / \mathrm{l})$, NEFA $(\mathrm{mmol} / \mathrm{l})$ and lactate $(\mathrm{mg} / \mathrm{dl})$ were analysed using the commercial assay kits TP 1630, RB 1007, NEFA FA115 and Lactate LC 2389 (Randox Laboratories Ltd), respectively. Lactose and TAG were analysed using the ELISA method modified from Arthur et al. ${ }^{(27)}$ and Cox et al. ${ }^{(28)}$, respectively. Energy level (kcal) was determined on the basis of the equation presented earlier.

\section{Data analysis}

Summary statistics are expressed as means and standard deviations. Student's $t$ test was utilized to compare differences in blood and milk composition between baseline and specific time points post-treatment. The paired $t$ test was applied to test the significance of exposed (CSSR) and control (NASC) groups. A value of $P<0.05$ (two-tailed) was considered statistically significant.

\section{Results}

Table 1 presents the macronutrient levels in the two soups under evaluation. CSSR had a significantly lower water content $(P<0.05, t$ test $)$ but significantly higher crude fat and energy levels $(P<0 \cdot 05, t$ test $)$ than NASC. The discrepancy in water content was due to the fact that CSSR was made with rice wine (containing 19.5\% alcohol), while NASC used $100 \%$ water in the preparation. The higher crude fat level in CSSR can be explained by the greater amount of fatty acids (originating from the fat of chicken meat) produced in the alcoholic medium. Higher fat and alcohol level in CSSR resulted in higher overall energy level than that in NASC.

Table 2 shows mean concentrations of constituents identified in the blood of twenty-three lactating mothers after consuming soup with alcohol dosage of $0.3 \mathrm{~g} / \mathrm{kg}$ body weight or non-alcoholic control soup. At $150 \mathrm{~min}$ after soup consumption, concentrations of TAG, insulin and lactate in blood revealed statistically significant differences $(P<0 \cdot 05$, paired $t$ test) between the CSSR and NASC groups.

Table 3 displays the mean concentrations of various constituents in the breast milk of twenty-three lactating women after consuming CSSR (alcohol dosage $0.3 \mathrm{~g} / \mathrm{kg}$ body weight) or NASC. Concentrations of TAG and lactate differed significantly $(P<0 \cdot 05$, paired $t$ test) between the CSSR and NASC groups at the end of the experiment (135 min).

Table 4 presents mean lactation parameters, i.e. the volume excreted and the time required for ejection of the first droplet of breast milk, in the twenty-three lactating women after consuming CSSR or NASC. The results revealed that mothers consuming CSSR required a significantly longer time $(P<0 \cdot 05)$ until ejection of the first milk droplet than mothers consuming the non-alcoholic soup ( $4.4 v .2 .9 \mathrm{~min}$ ), while the total volume excreted by the CSSR group was less than that excreted by the NASC group $(41.3 v .47 \cdot 6 \mathrm{ml})$ but the difference did not reach statistical significance $(P>0 \cdot 05)$. Moreover, milk yields were not correlated with alcohol levels in blood or milk (detailed data not shown).

Table 1 Macronutrient levels in the alcoholic and non-alcoholic soups

\begin{tabular}{|c|c|c|c|c|}
\hline \multirow[b]{2}{*}{ Nutrient } & \multicolumn{2}{|c|}{ NASC (non-alcoholic) } & \multicolumn{2}{|c|}{ CSSR (alcoholic) } \\
\hline & Mean & SD & Mean & SD \\
\hline Water (g/dl) & $90 \cdot 8$ & 0.02 & $83 \cdot 7^{\star}$ & 0.00 \\
\hline Crude ash (g/dl) & 0.42 & 0.02 & $0 \cdot 41$ & 0.01 \\
\hline Crude protein (g/dl) & $1 \cdot 39$ & 0.01 & $1 \cdot 39$ & 0.01 \\
\hline Crude fat $(\mathrm{g} / \mathrm{dl})$ & $1 \cdot 10$ & $0 \cdot 10$ & $1 \cdot 95^{\star}$ & $0 \cdot 12$ \\
\hline Carbohydrates (g/dl) & $1 \cdot 67$ & 0.03 & $1 \cdot 51$ & 0.03 \\
\hline Energy (kJ/dl) & $94 \cdot 6$ & $4 \cdot 4$ & $120 \cdot 5^{\star}$ & $4 \cdot 4$ \\
\hline Energy (kcal/dl) & $22 \cdot 6$ & $1 \cdot 10$ & $28 \cdot 8^{*}$ & $1 \cdot 10$ \\
\hline
\end{tabular}

NASC, non-alcoholic sesame oil-flavoured chicken soup; CSSR, chicken soup flavoured with sesame oil and rice wine.

*Mean values were significantly different from those of the control (NASC) group: $P<0.05$ ( $t$ test). 
Table 2 Mean concentrations of constituents in blood samples of twenty-three lactating women after consuming soup containing $0.3 \mathrm{~g}$ alcohol/kg body weight $v$. non-alcoholic control soup

\begin{tabular}{|c|c|c|c|c|c|c|c|c|}
\hline \multirow[b]{3}{*}{ Constituent } & \multicolumn{4}{|c|}{ NASC (non-alcoholic) } & \multicolumn{4}{|c|}{ CSSR (alcoholic) } \\
\hline & \multicolumn{2}{|c|}{ Baseline } & \multicolumn{2}{|c|}{$150 \mathrm{~min}$} & \multicolumn{2}{|c|}{ Baseline } & \multicolumn{2}{|c|}{$150 \min$} \\
\hline & Mean & SD & Mean & SD & Mean & SD & Mean & SD \\
\hline TAG (mg/dl) & $103 \cdot 1$ & $67 \cdot 3$ & $99 \cdot 2$ & $66 \cdot 0$ & $108 \cdot 5$ & $77 \cdot 9$ & $121 \cdot 4 \ddagger$ & $72 \cdot 6$ \\
\hline Total protein $(\mathrm{mg} / \mathrm{dl})$ & $7 \cdot 1$ & 0.4 & $6 \cdot 8 \dagger$ & 0.4 & $7 \cdot 2$ & $0 \cdot 3$ & $6.9+$ & 0.5 \\
\hline Glucose (mg/dl) & $86 \cdot 0$ & $11 \cdot 1$ & $84 \cdot 0$ & $6 \cdot 6$ & $84 \cdot 7$ & $7 \cdot 7$ & $81 \cdot 3$ & $9 \cdot 7$ \\
\hline Cholesterol (mg/dl) & $190 \cdot 1$ & $40 \cdot 7$ & $177 \cdot 0 t$ & $35 \cdot 5$ & $186 \cdot 6$ & $33 \cdot 0$ & $170 \cdot 8+$ & $33 \cdot 2$ \\
\hline GOT (U/I) & $21 \cdot 8$ & $7 \cdot 3$ & $22 \cdot 8$ & $7 \cdot 6$ & $23 \cdot 0$ & $6 \cdot 7$ & $23 \cdot 5$ & $9 \cdot 0$ \\
\hline GPT (U/I) & $28 \cdot 4$ & $11 \cdot 2$ & $26 \cdot 5$ & $13 \cdot 4$ & $29 \cdot 1$ & $11 \cdot 8$ & $27 \cdot 1+$ & $13 \cdot 6$ \\
\hline Insulin $(\mu \mathrm{U} / \mathrm{I})$ & $6 \cdot 7$ & $5 \cdot \overline{9}$ & $4 \cdot 6+$ & $3 \cdot 2$ & $6 \cdot 4$ & $6 \cdot 1$ & $6 \cdot 8 \ddagger$ & $4 \cdot 3$ \\
\hline Prolactin (ng/ml) & $158 \cdot 3$ & $132 \cdot 7$ & $156 \cdot 0$ & $107 \cdot 3$ & $148 \cdot 8$ & $101 \cdot 2$ & $178 \cdot 9$ & $118 \cdot 0$ \\
\hline NEFA (mmol/l) & 0.5 & $0 \cdot 1$ & $0.9+$ & $0 \cdot 4$ & 0.5 & $0 \cdot 1$ & $0 \cdot 8+$ & 0.5 \\
\hline$\beta$-Hydroxybutyrate $(\mathrm{mmol} / \mathrm{l})$ & $1 \cdot 3$ & 0.5 & $1 \cdot 2$ & 0.5 & $1 \cdot 2$ & 0.7 & $1 \cdot 2$ & $0 \cdot 7$ \\
\hline Lactate (mg/dl) & $9 \cdot 6$ & $4 \cdot 2$ & $6 \cdot 2 \dagger$ & $3 \cdot 0$ & $10 \cdot 0$ & $4 \cdot 1$ & $9 \cdot 0 \ddagger$ & $2 \cdot 8$ \\
\hline 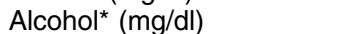 & NM & - & NM & - & 4.83 & $1 \cdot 23$ & $9 \cdot 78$ & $4 \cdot 52$ \\
\hline
\end{tabular}

NASC, non-alcoholic sesame oil-flavoured chicken soup; CSSR, chicken soup flavoured with sesame oil and rice wine; GOT, glutamic oxaloacetic transaminase; GPT, glutamic pyruvic transaminase; NM, not measured.

${ }^{*}$ From Chien et al. ${ }^{(13)}$. Note: the lower limit of the reportable range for blood alcohol level was $10 \mathrm{mg} / \mathrm{dl}$.

tMean values were significantly different from those at baseline: $P<0.05$ (paired $t$ test).

¥Mean values were significantly different from those of the control (NASC) group: $P<0.05$ (paired $t$ test).

Table 3 Mean concentrations of constituents in breast milk* of twenty-three lactating mothers after consuming soup containing $0.3 \mathrm{~g}$ alcohol/kg body weight $v$. non-alcoholic control soup

\begin{tabular}{|c|c|c|c|c|c|c|c|c|}
\hline \multirow[b]{3}{*}{ Constituent } & \multicolumn{4}{|c|}{ NASC (non-alcoholic) } & \multicolumn{4}{|c|}{ CSSR (alcoholic) } \\
\hline & \multicolumn{2}{|c|}{ Baseline } & \multicolumn{2}{|c|}{$135 \mathrm{~min}$} & \multicolumn{2}{|c|}{ Baseline } & \multicolumn{2}{|c|}{$135 \mathrm{~min}$} \\
\hline & Mean & SD & Mean & SD & Mean & SD & Mean & SD \\
\hline Total protein $(\mathrm{mg} / \mathrm{dl})$ & $17 \cdot 0$ & $2 \cdot 5$ & $18 \cdot 4 \ddagger$ & $2 \cdot 6$ & $17 \cdot 7$ & $3 \cdot 5$ & $18 \cdot 9 \ddagger$ & $3 \cdot 9$ \\
\hline TAG (mg/dl) & $8 \cdot 7$ & $2 \cdot 3$ & $12 \cdot 3 \ddagger$ & $3 \cdot 1$ & $9 \cdot 6$ & $2 \cdot 7$ & $14 \cdot 8 \ddagger, \S$ & $3 \cdot 2$ \\
\hline Lactose (g/dl) & $6 \cdot 7$ & 0.5 & $6 \cdot 6$ & 0.5 & $6 \cdot 7$ & 0.6 & $6 \cdot 6 \ddagger$ & 0.5 \\
\hline Energy $(\mathrm{kJ} / \mathrm{dl})$ & $468 \cdot 6$ & $87 \cdot 9$ & $602 \cdot 9$ & $118 \cdot 8$ & $504 \cdot 6$ & $102 \cdot 9$ & $697 \cdot 9$ & $119 \cdot 7$ \\
\hline Energy (kcal/dl) & $112 \cdot 0$ & $21 \cdot 0$ & $144 \cdot 1$ & $28 \cdot 4$ & $120 \cdot 6$ & $24 \cdot 6$ & $166 \cdot 8$ & $28 \cdot 6$ \\
\hline $\operatorname{EGF}(\mathrm{ng} / \mathrm{dl})$ & $36 \cdot 2$ & $14 \cdot 3$ & $36 \cdot 1$ & $19 \cdot 7$ & $41 \cdot 1$ & $30 \cdot 5$ & $47 \cdot 3$ & $35 \cdot 5$ \\
\hline NEFA (mmol/l) & $0 \cdot 1$ & $0 \cdot 1$ & $0 \cdot 2 \ddagger$ & $0 \cdot 1$ & $0 \cdot 1$ & $0 \cdot 1$ & $0 \cdot 2 \ddagger$ & $0 \cdot 1$ \\
\hline$\beta$-Hydroxybutyrate $(\mathrm{mmol} / \mathrm{l})$ & 0.4 & $0 \cdot 2$ & 0.5 & $0 \cdot 3$ & 0.5 & $0 \cdot 4$ & $0 \cdot 7 \ddagger$ & 0.6 \\
\hline Lactate (mg/dl) & 0.5 & 0.2 & $0.6 \ddagger$ & $0 \cdot 4$ & $0 \cdot 6$ & $0 \cdot 8$ & $0 \cdot 8 \ddagger, \S$ & 0.6 \\
\hline Alcoholt (mg/dl) & NM & - & NM & - & 0.36 & 0.90 & $9 \cdot 05 \ddagger$ & $5 \cdot 21$ \\
\hline
\end{tabular}

NASC, non-alcoholic sesame oil-flavoured chicken soup; CSSR, chicken soup flavoured with sesame oil and rice wine; EGF, epidermal growth factor; NM, not measured.

${ }^{*}$ Milk was emptied from both breasts at $120 \mathrm{~min}$ post-exposure and pooled. Since this procedure took $30 \mathrm{~min}$ (15 min for each breast), the mid-point (135 min) was adopted as the sampling time.

tFrom Chien et al. ${ }^{(13)}$. Note: the detection limit of the method for milk alcohol level was $2 \cdot 47 \mathrm{mg} / \mathrm{dl}$.

¥Mean values were significantly different from those at baseline: $P<0.05$ (paired $t$ test).

$\S$ Mean values were significantly different from those of the control (NASC) group: $P<0.05$ (paired $t$ test).

\section{Discussion}

\section{Influence of alcobolic diet on maternal blood composition}

The pharmacokinetics of alcohol in milk and blood after CSSR consumption and its implications have been described in detail elsewhere ${ }^{(13)}$. Briefly, milk alcohol peaked at 20-40 min, decreased nearly linearly thereafter, and reached zero level at approximately $175 \mathrm{~min}$ postconsumption. Blood alcohol levels followed a similar pattern as in milk but increased to a maximum at $20 \mathrm{~min}$. Large variations in milk (mean $44.4 \%$ ) and blood (mean $30 \cdot 0 \%$ ) alcohol level were noted among subjects. At
135 min after consumption of CSSR, the alcohol levels in milk were significantly higher than at baseline (Table 3).

In the current study, mean levels of total protein and cholesterol in blood at $150 \mathrm{~min}$ post-consumption of CSSR and NASC were significantly different (lower) from their corresponding baseline levels, while NEFA levels increased compared with baseline (Table 2). Conversely, at $150 \mathrm{~min}$ post-consumption of CSSR or NASC, concentrations of TAG, insulin and lactate in maternal blood exhibited statistically significant differences between the two groups (Table 2). These differences can be explained by the following mechanism. The oxidation of ethanol produces acetyl-CoA, which is in turn converted into 
Table 4 Mean lactation parameters of twenty-three lactating women after consuming soup containing $0.3 \mathrm{~g}$ alcohol $/ \mathrm{kg}$ body weight $v$. non-alcoholic control soup

\begin{tabular}{lrrrrr}
\hline & \multicolumn{2}{c}{ NASC (non-alcoholic) } & & \multicolumn{2}{c}{ CSSR (alcoholic) } \\
\cline { 2 - 3 } \cline { 5 - 6 } Lactation performance & Mean & SD & & Mean & \multicolumn{1}{c}{ SD } \\
\hline Time to eject $(\mathrm{s})^{*}$ & 2.9 & 1.7 & & $4.4+$ & 2.8 \\
Volume excreted $(\mathrm{ml})^{*}$ & 47.6 & 33.9 & & 41.3 & 28.9 \\
\hline
\end{tabular}

NASC, non-alcoholic sesame oil-flavoured chicken soup; CSSR, chicken soup flavoured with sesame oil and rice wine.

${ }^{*}$ At 120 min after consuming CSSR or NASC, milk was emptied from both breasts (15 $\mathrm{min}$ for each breast) using an electric breast pump. Volume excreted and time required for the first milk droplet to be ejected were recorded.

tMean values were significantly different from those of the control (NASC) group: $P<0.05$ (paired $t$ test).

NEFA and TAG. Meanwhile, lactate in the blood increases in response to the temporally unbalanced oxidation/ reduction status in the body resulting from ethanol metabolism ${ }^{(29)}$.

\section{Influence of alcobolic diet on milk composition}

Lactation is a multistage process characterized by increased demand for metabolic substrates to provide the constituents such as lactose, lipid and protein of milk ${ }^{(17,30,31)}$. Mean levels of total protein, TAG, NEFA, $\beta$-hydroxybutyrate and lactate in milk at $135 \mathrm{~min}$ postconsumption of CSSR and NASC differed significantly from their corresponding baseline levels (Table 3), indicating that ingestion of the soups affected milk composition and thus its nutritional status, at least in the short term.

Conversely, mean concentrations of TAG and lactate in milk at $135 \mathrm{~min}$ post-consumption (Table 3) revealed statistically significant differences between the two treatments. Such differences were also observed in blood (Table 2), indicating that the milk constituents are a function of blood substrate levels which in turn are affected by diet. However, no significant difference was observed in milk energy levels between the two groups. These findings are compatible with earlier experimental results. For example, ethanol intake during lactation has been found to alter lipid metabolism in rats, as indicated by an increased lipogenesis rate in vivo in the mammary gland and its lipid content ${ }^{(18-20)}$. Rat studies revealed that chronic ethanol ingestion during gestation and lactation also alters mammary gland function, resulting in lower total milk production ${ }^{(20)}$. The milk from ethanol-fed rats had increased $\mathrm{pH}$, protein and lipids and decreased lactose compared with controls ${ }^{(19)}$. This evidence clearly shows that ethanol intake during lactation alters breast milk composition, even though the current findings may be confounded by the higher fat and energy contents in the exposed group (CSSR) than in the control (Table 1). Accordingly, further investigation is needed to address this uncertainty.

\section{Influence of alcobolic diet on lactation performance}

Lactation is a hormone-mediated process. Oxytocin is responsible for ejection of milk from the mammary gland, and prolactin promotes milk synthesis ${ }^{(32)}$. Numerous studies have found that ethanol blocks oxytocin release and inhibits the milk-ejecting reflex in lactating mothers. For example, an ethanol dose of $>1.0 \mathrm{~g} / \mathrm{kg}$ significantly inhibited milk-ejecting activities (measured via intra-mammary and intra-uterine pressure changes) and the inhibition correlated with administered ethanol dose more closely than with blood ethanol levels ${ }^{(23)}$. Studies have also demonstrated that suckling-induced oxytocin levels are attenuated following ethanol consumption in non-lactating women $^{(22)}$ and lactating rats ${ }^{(17-21)}$. Similarly, the present study found a statistically significant increase $(\sim 52 \%, 4 \cdot 4$ v. $2.9 \mathrm{~min}, P<0.05$ ) in the time for ejection of the first milk droplet in the exposed (CSSR) group in comparison with the non-alcoholic diet group. This difference indicates that the milk-ejecting reflex is affected at the dose level of $0.3 \mathrm{~g}$ alcohol/kg body weight. A comparable study also identified an increase $(\sim 12 \%)$ in the time until ejection of the first milk droplet after alcohol consumption, although the increase was not statistically significant ${ }^{(24)}$. Direct inhibition of the central nervous system or impairment of the neurotransmission of infant suckling to the posterior pituitary is the potential mechanism blocking oxytocin release and inhibiting the milk-ejecting reflex ${ }^{(33)}$.

Conversely, although prolactin is considered essential for maintaining long-term lactation ${ }^{(28,34)}$, previous studies of blood prolactin pharmacokinetics, both in men and nonlactating women, have shown that ethanol consumption generally increases plasma prolactin levels ${ }^{(35-39)}$. This trend towards increased blood prolactin levels after alcohol exposure was also observed in the current study although the increase was not statistically significant (from $148 \cdot 8$ to $178.9 \mathrm{ng} / \mathrm{ml}$, Table 2). Conversely, animal studies have revealed decreased suckling-induced prolactin excretion after ethanol administration ${ }^{(40,41)}$. Accordingly, no clear temporal correlation can be established between blood prolactin levels and alcohol administration.

Milk yield has also been studied as an indicator of lactation performance. A study of twenty-one mothers demonstrated a statistically significant reduction $(\sim 22 \%)$ in milk yield at $2 \mathrm{~h}$ after maternal ingestion of alcohol in juice at $0 \cdot 3 \mathrm{~g} / \mathrm{kg}^{(24)}$. Animal studies further indicated that chronic ethanol consumption reduced milk yields ${ }^{(19)}$. The present investigation also revealed excretion of less milk ( $\sim 15 \%$, Table 4$)$ at $2 \mathrm{~h}$ after CSSR consumption compared with the NASC group; however, the differences were not statistically significant. Such decreases in milk yields in the current study were not found to be correlated with alcohol levels in blood or milk.

As previous studies have demonstrated that milk content can be affected by ethanol intake, the present study accounted for four factors impacting alcohol absorption 
and pharmacokinetics: (i) alcohol doses were administered based on the subjects' body weight; (ii) the time alcohol remained in the gastrointestinal tract was controlled by administering two servings of cereal prior to alcohol consumption; (iii) the rate at which alcohol was consumed was controlled as subjects were required to consume their soup within $15 \mathrm{~min}$; and (iv) repeated within-subject measurement was applied to control for intra-individual variation.

Additionally, it is known that the composition of milk is not constant. For example, the fat content exhibits large diurnal variations and increases during the course of each nursing, although it does not vary consistently during lactation $^{(42-45)}$. Milk lipids are affected by maternal diet ${ }^{(43,46)}$; therefore, the randomized repeated measurement design utilized in the current study is beneficial to control for the intra-individual variation potentially resulting from diet. Furthermore, as previous studies have demonstrated that total fatty acid composition remains uniform between 2 and 16 weeks postpartum ${ }^{(47,48)}$ and milk TAG remains constant after the first week postpartum ${ }^{(49)}$, the current finding of significant change in milk TAG after CSSR consumption is less likely to result from maternal diet.

\section{Conclusions}

Tso-Yueh-Tzu ('doing the month') is an important Chinese cultural practice deemed beneficial for convalescing new mothers. Although contemporary Chinese women question certain taboos in 'doing the month' such as refraining from washing the hair for an entire month ${ }^{(14,50)}$, eating prescribed foods such as CSSR remains a crucial practice in the TsoYueh-Tzu ritual ${ }^{(14,51-53)}$. Previous study has demonstrated the potential transfer of alcohol through the mothermilk-infant pathway after consumption of a typical diet, CSSR, during the 'doing-the-month' period ${ }^{(13)}$. The present investigation further examined whether CSSR consumption affects lactation parameters.

Ingestion of both soups during lactation affected maternal metabolism of certain constituents such as lipids, resulting in changes in levels detected in the blood. Consumption of alcoholic soup influenced TAG, insulin and lactate levels in maternal blood compared with the non-alcoholic preparation. Likewise, ingestion of the soups affected milk composition and its nutritional status, particularly total protein, TAG, NEFA, $\beta$-hydroxybutyrate and lactate levels. Intake of alcoholic soup during lactation significantly impacted TAG and lactate levels in the milk. The time until ejection of the first milk droplet was significantly longer in the alcoholic diet group, indicating that at the current dose level $(0.3 \mathrm{~g}$ alcohol $/ \mathrm{kg}$ body weight $)$ the milk-ejecting reflex is inhibited. However, blood prolactin, a hormone essential for maintaining long-term lactation level, increased slightly after ethanol intake. Milk yields were affected by the alcoholic soup, but the influence was not statistically significant. Nevertheless, as the current study focused on short-term effects, complementary studies with a longer follow-up would be useful to elucidate the long-term effects of an alcoholic diet on the composition of breast milk and breast-feeding characteristics.

Maternal alcohol ingestion during lactation has no proven benefit to either infants or mothers. Conversely, previous studies have clearly demonstrated that alcohol ingested by lactating mothers can be passed to infants and negatively affect their short-term physiological response and long-term development. Such facts, in conjunction with the current findings that alcohol impacts lactation, suggest that ingestion of alcoholic drinks/foods should be avoided during lactation.

\section{Acknowledgement}

Sources of funding: Financial supports for the study came partially from the National Science Council (Taiwan, Republic of China; Grant NSC91-2815-C-241-006-E), Hungkuang Committee of Academic and Research Development (Grant\# HKC-89-B-004) and internal funds from Taipei Medical University.

Conflict of interest declaration: None declared.

Authorship responsibilities: Y.-C.C. conceived the study hypothesis, performed data analyses and prepared the manuscript; Y.-J.H. implemented the experiment and collected data; C.-S.H. recruited study subjects and supervised their health status; J.C.-J.C. offered details in human sample collection and analysis; J.-F.L. supervised the study design, data interpretation and implication.

Acknowledgement: Participation of the study subjects is gratefully acknowledged.

\section{References}

1. US Department of Health and Human Services (2000) HHS Blueprint for Action on Breastfeeding. Washington, DC: US DHHS, Office on Women's Health.

2. Ito S (2000) Drug therapy for breast-feeding women. $N$ Engl J Med 343, 118-126.

3. Liston J (1998) Breastfeeding and the use of recreational drugs - alcohol, caffeine, nicotine and marijuana. Breastfeed Rev 6, issue 2, 27-30.

4. Work Group on Breastfeeding, American Academy of Pediatrics (1997) Breast feeding and the use of human milk. Pediatrics 100, 1035-1039.

5. Rogan WJ (1996) Pollutants in breast milk. Arch Pediatr Adolesc Med 150, 981-990.

6. Somogyi A \& Beck H (1993) Nurturing and breast-feeding: exposure to chemicals in breast milk. Environ Health Perspect 101, Suppl. 2, 45-52.

7. Coveney J (1985) Is breast milk the best food for all infants? Human Nutr Appl Nutr 39A, 179-188.

8. Argote-Espinosa RM, Flores-Huerta S, Hernandez-Montes H \& Villalpando-Hernandez S (1992) Plasma clearance of ethanol and its excretion in the milk of rural women who consume pulque. Rev Invest Clin 44, 31-36.

9. Mennella JA \& Beauchamp GK (1991) The transfer of alcohol to human milk: effects on flavor and the infant behavior. $N$ Engl J Med 325, 981-985. 
10. Flores-Heurta S, Hernandez-Montes H, Argote RM \& Villalpando S (1992) Effects of ethanol consumption during pregnancy and lactation on the outcome and postnatal group of the offspring. Ann Nutr Metab 36, 121-128.

11. Walter M (1975) The folklore of breastfeeding. Bull NY Acad Med 51, 870-876.

12. Adams LM \& Davidson M (1987) Present concepts of infant colic. Pediatr Ann 16, 817-820.

13. Chien YC, Liu JF, Huang YJ, Hsu CS \& Chao JCJ (2005) Alcohol levels in Chinese lactating mothers after consumption of alcoholic diet during postpartum 'doing-the-month' ritual. Alcohol 37, 143-150.

14. Liu-Chiang CY (1995) Postpartum worries: an exploration of Taiwanese primiparas who participate in the Chinese ritual of Tso-Yueh-Tzu. Matern Child Nurs J 23, 110-122.

15. Mennella JA \& Gerrish CJ (1998) Effects of exposure to alcohol in mother's milk on infant sleep. Pediatrics 101, 21-25.

16. Little RE, Anderson $\mathrm{KW}$, Ervin $\mathrm{CH}$, Worthington-Roberts $\mathrm{B}$ \& Clarren SK (1989) Maternal alcohol use during breastfeeding and infant mental and motor development at one year. $N$ Engl J Med 321, 425-430.

17. Heil SH, Hungund BL, Zheng ZH, Jen KL \& Subramanian MG (1999) Ethanol and lactation: effects on milk lipids and serum constituents. Alcohol 18, 43-48.

18. Tavares do Carmo MG \& Nascimento-Cui CMO (1990) Effects of ethanol intake during lactation on the metabolism of dams and pup development. Braz J Med Biol Res 23, 1161-1163.

19. Sanchis R \& Guerri C (1986) Chronic ethanol intake in lactating rats: milk analysis. Comp Biochem Physiol C 85, 107-110.

20. Vilaro S, Vinas O, Remesar X \& Herrera E (1987) Effects of chronic ethanol consumption on lactational performance in rat: mammary gland and milk composition and pups' growth and metabolism. Pharmacol Biochem Behav 27, 333-339.

21. Subramanian MG (1999) Alcohol inhibits suckling-induced oxytocin release in the lactating rat. Alcohol 19, 51-55.

22. Coiro V, Alboni A, Gramellini D, Cigarini C, Bianconi L, Pignatti D, Volpi R \& Chiodera P (1992) Inhibition by ethanol of the oxytocin response to breast stimulation in normal women and the role of endogenous opioids. Acta Endocrinol (Copenh) 26, 213-216.

23. Cobo E (1973) Effects of different doses of ethanol on the milk-ejecting reflex in lactating women. Am J Obstet Gynecol 115, 817-821.

24. Mennella JA (1998) Short-term effects of maternal alcohol consumption on lactational performance. Alcohol Clin Exp Res 22, 1389-1392.

25. Jones AW, Jonsson KA \& Kechagias S (1997) Effect of highfat, high-protein, and high-carbohydrate meals on the pharmacokinetics of a small dose of ethanol. $\mathrm{Br} \mathrm{J} \mathrm{Clin}$ Pharmacol 44, 521-526.

26. Association of Official Analytical Chemists (1980) Official Methods of Analysis, 13th ed. Washington, DC: AOAC.

27. Arthur PG, Smith M \& Hartmann PE (1989) Milk lactose, citrate and glucose as markers of lactogenesis in normal and diabetic women. J Pediatr Gastroenterol Nutr 9, 488-496.

28. Cox DB, Owens RA \& Hartmann PE (1996) Blood and milk prolactin and the rate of milk synthesis in women. Exp Physiol 81, 1007-1020.

29. Forsander OA (1970) Influence of ethanol and butyraldoxime on liver metabolism. Biochem Pharmacol 19, 2131-2136.

30. Oyama LM, Couto RC, Couto GEC, Damaso AR \& Oller do Nascimento CM (2000) Ethanol intake during lactation I. Effects on dams' metabolism and pups' body weight gain. Alcohol 21, 195-200.
31. Kunz C, Rodriguez-Palmero M, Koletzko B \& Jensen R (1999) Nutritional and biochemical properties of human milk, Part I: General aspects, proteins, and carbohydrates. Clin Perinatol 26, 307-333.

32. Short RV (1984) Breast feeding. Sci Am 250, 35-41.

33. Fuchs AR (1969) Ethanol and the inhibition of oxytocin release in lactating rats. Acta Endocrinol (Copenh) 62, 546-554.

34. Mennella JA (2003) Alcohol use during lactation: effects on the mother and the breastfeeding infant. In Nutrition and Alcohol: Linking Nutrient Interactions and Dietary Intake, pp. 377-391 [RR Watson and VR Preedy, editors]. Boca Raton, FL: CRC Press.

35. Volpi R, Chiodera P, Gramellini D, Cigarini C, Papadia C, Caffarri G, Rossi G \& Coiro V (1994) Endogenous opioid mediation of the inhibitory effect of ethanol on the prolactin response to breast stimulation in normal women. Life Sci 54, 739-744.

36. Soyka M, Gorig E \& Naber D (1991) Serum prolactin increase induced by ethanol - a dose-dependent effect not related to stress. Psychoneuroendocrinology 16, 441-446.

37. Carlson HE, Lamberts SW, Brickman AS, Deftos LJ, Horst RL \& Forte LR (1985) Hypercalcemia in rats bearing growth hormone- and prolactin-secreting transplantable pituitary tumors. Endocrinology 117, 1602-1607.

38. De Rosa G, Corsello SM, Ruffilli MP, Della Casa S \& Pasargiklian E (1981) Prolactin secretion after beer. Lancet 2, 934-937.

39. Earll JM, Gaunt K, Earll LA \& Djuh YY (1976) Effect of ethyl alcohol on ionic calcium and prolactin in man. Aviat Space Environ Med 47, 808-810.

40. Subramanian MG, Chen XG \& Bergeski BA (1990) Pattern and duration of the inhibitory effect of alcohol administered acutely on suckling-induced prolactin in lactating rats. Alcohol Clin Exp Res 14, 771-775.

41. Subramanian MG \& Abel EL (1988) Alcohol inhibits suckling-induced prolactin release and milk yield. Alcohol $\mathbf{5}, 95-98$

42. Mitoulas LR, Kent JC, Cox DB, Owens RA, Sherriff JL \& Hartmann PE (2002) Variation in fat, lactose and protein in human milk over $24 \mathrm{~h}$ and through the first year of lactation. Br J Nutr 88, 29-37.

43. Jensen RG (1996) The lipids in human milk. Prog Lipid Res 35, 53-92.

44. Lammi-Keefe CJ, Ferris AM \& Jensen RG (1990) Changes in human milk at 0600, 1000, 1400, 1800, and $2000 \mathrm{~h}$. J Pediatr Gastroenterol Nutr 11, 83-88.

45. Jenness R (1979) The composition of human milk. Semin Perinatol 3, 225-239.

46. Jensen RG (1999) Lipids in human milk. Lipids 34, 1243-1271.

47. Clark RM, Ferris AM, Fey M, Brown PB, Hundrieser KE \& Jensen RG (1982) Changes in the lipids of human milk from 2 to 16 weeks postpartum. J Pediatr Gastroenterol Nutr $\mathbf{1}$, 311-315.

48. Jensen RG (1980) Composition of the lipids in human milk: a review. Lipids 15, 345-355.

49. Harzer G, Haug M \& Bindels JG (1986) Biochemistry of human milk in early lactation. Z Ernabrungswiss 25, 77-90.

50. Leung SK, Arthur D \& Martinson IM (2005) Perceived stress and support of the Chinese postpartum ritual 'doing the month'. Health Care Women Int 26, 212-224.

51. Chan SM, Nelson EA, Leung SS, Cheung PC \& Li CY (2000) Special postpartum dietary practices of Hong Kong Chinese women. Eur J Clin Nutr 54, 797-802.

52. Holroyd E, Katie FK, Chun LS \& Ha SW (1997) 'Doing the month': an exploration of postpartum practices in Chinese women. Health Care Women Int 18, 301-313.

53. Whang J (1981) Chinese traditional food therapy. J Am Diet Assoc 78, 55-57. 